\title{
THE ROYAL MATERNITY CHARITY: THE FIRST HUNDRED YEARS
}

by

\author{
STANLEY A. SELIGMAN*
}

\section{FORMATION OF THE CHARITY}

The eighteenth century saw the introduction on a large scale of skilled maternity care for the poor of London. Before that time, pregnant women had been specifically excluded from general hospitals, and their only resource had been the workhouse which was used as a lying-in infirmary - or the attention of those who often combined the nursing of lying-in women with the hawking of fish or vegetables or with other less reputable occupations. ${ }^{1}$ In 1716, the Westminster Charitable Society launched a scheme for the lodging, maintenance, and treatment of poor lying-in women in the parish of St. Margaret. ${ }^{2}$ In 1739, Sir Richard Manningham took an apartment to accommodate 300 women a year, combining charity with instruction in the art and practice of midwifery of young physicians, surgeons, and women. ${ }^{3}$ Other obstetricians followed his example, including William Smellie," who in 1742 advertised that: "He has houses where poor women with child are delivered, at which deliveries those who are his pupils may, on reasonable terms, be present."

In 1747, five beds were reserved for lying-in patients at the Middlesex Hospital, ${ }^{5}$ founded two years previously. The first maternity hospital in London, the Lying-in Hospital, opened with twenty beds in 1749,6 later becoming the British Lying-inHospital for Married Women. In the following year, 1750, the Lying-in Hospital for Married Women in the City of London, also for Sick and Lame Out-patients, was founded. ${ }^{7}$ The out-patient work was given up a year later, and the hospital eventually became the City of London Maternity Hospital.

The confusion concerning the opening of the General Lying-in Hospital (later the Queen's Hospital, now Queen Charlotte's Hospital) has been dispelled following the

\footnotetext{
* Stanley A. Seligman, M.D., F.R.C.S., F.R.C.O.G., Department of Obstetrics, Luton and Dunstable Hospital, Dunstable Road, Luton, Beds LU4 0DZ.

${ }^{1}$ M. Dorothy George, London life in the eighteenth century, Harmondsworth, Penguin, 1966, pp. 60-61.

${ }^{2}$ G. C. Peachey, 'Note upon the provision for lying-in women in London up to the middle of the eighteenth century', Proc. Roy. Soc. Med., 1924, 17: 72-75.

${ }^{3}$ Ibid.

4 Ibid.

'Alistair Gunn, 'Maternity hospitals', in F. N. L. Poynter (editor), The evolution of hospitals in Britain, London, Pitman Medical Publishing Company, 1964, pp. 77-101.

' Ibid.

' Ibid.
} 
acquisition of a pamphlet 8.9 by the Wellcome Institute Library. This states that the Hospital was founded in Jermyn Street, in 1752, not 1739 as had been previously suggested by Peachey. ${ }^{10}$

The last of the great London maternity hospitals, the New Westminster Lying-in Hospital, later the General Lying-in Hospital, was opened in $1765,{ }^{11}$ admitting unmarried women from the beginning.

The Charity for Attending and Delivering poor Married Women in their Lying-in at their Respective Habitations was inaugurated on 25 March 1757. Nothing else is known of the early days of what was to become the Royal Maternity Charity until 1761 , when the first minutes of the Charity were recorded. The minute books, except for one missing volume spanning the years 1830-1832, are complete through to 1949, when the Charity disbanded. They are housed in the library of the Royal College of Obstetricians and Gynaecologists and provide the substance of this article. A number of other similar institutions for home delivery, sometimes associated with dispensaries, were instituted in the next half-century, and an incomplete list naming nine of these is given by Granville. ${ }^{12}$

It has become fashionable for social historians to question the motives of medical men in maternity hospitals in eighteenth-century London, attributing their initiatives as much to the imperatives of professionalism as to other considerations. ${ }^{13}$ As with the majority of the lying-in charities providing for home deliveries in that era, medical men were not involved as initiators of the Charity, they could not use the patients for teaching aspiring men-midwives, and they had no direct say in the running of the Charity, not being invited to attend the committee meetings until the society had been in existence for twenty-six years.

The instigator of the Charity was Mr. James Le Cour. Biographical details are lacking, but he was of Huguenot descent and his death notice described him as an "eminent jeweller", ${ }^{14}$ although he did not belong to the Goldsmiths' Company nor to the Gold and Silver Wyre Drawers. Jewellers did not have their own guild. Ambrose Heal, ${ }^{13}$ in his London goldsmiths 1200-1800, lists a David Le Cour, goldsmith, at Dorset Street, Spitalfields hamlet, in 1700, and a David Le Court [sic], jeweller, over against Drapers' Hall in Throgmorton Street 1718-1726, making it likely that James was carrying on a family business.

The first minuted meeting of subscribers to the Charity was held on 17 March 1761, at the Nags Head Tavern, Leaden Hall Street, the venue for meetings after that date

\footnotetext{
An account of the rise and progress of the lying-in hospital for married women in Brownlow Street. from its first institution in November, 1749, to December 25th, 1751, 1752.

9 J. E. Donnison, 'Note on the foundation of Queen Charlotte's Hospital', Med. Hist., 1971, 15: $398-400$.

${ }^{10} \mathrm{G}$. C. Peachey, 'Note upon the provision for lying-in women in London up to the middle of the eighteenth century', Proc. Roy. Soc. Med., 1924, 17: 72-75.

11 Philip Rhodes, Dr. John Leake's hospital, London, Davis-Poynter, 1977, p. 9.

12 Augustus Bozzi Granville, A report on the practice of midwifery at the Westminster General Dispensary during 1818, London, Burgess \& Hill, 1819, p. 3.

${ }_{13}$ Margaret A. Versluysen, 'Medical professionalism and maternity hospitals in eighteenth century London: a sociological interpretation', Soc. Social Hist. Med. Bull., 1977, 21: 34-36.

14 The London Magazine, 1767, p. 372.

1s Ambrose Heal, The London goldsmiths, 1200-1800, Cambridge University Press, 1935, p. 193.
} 

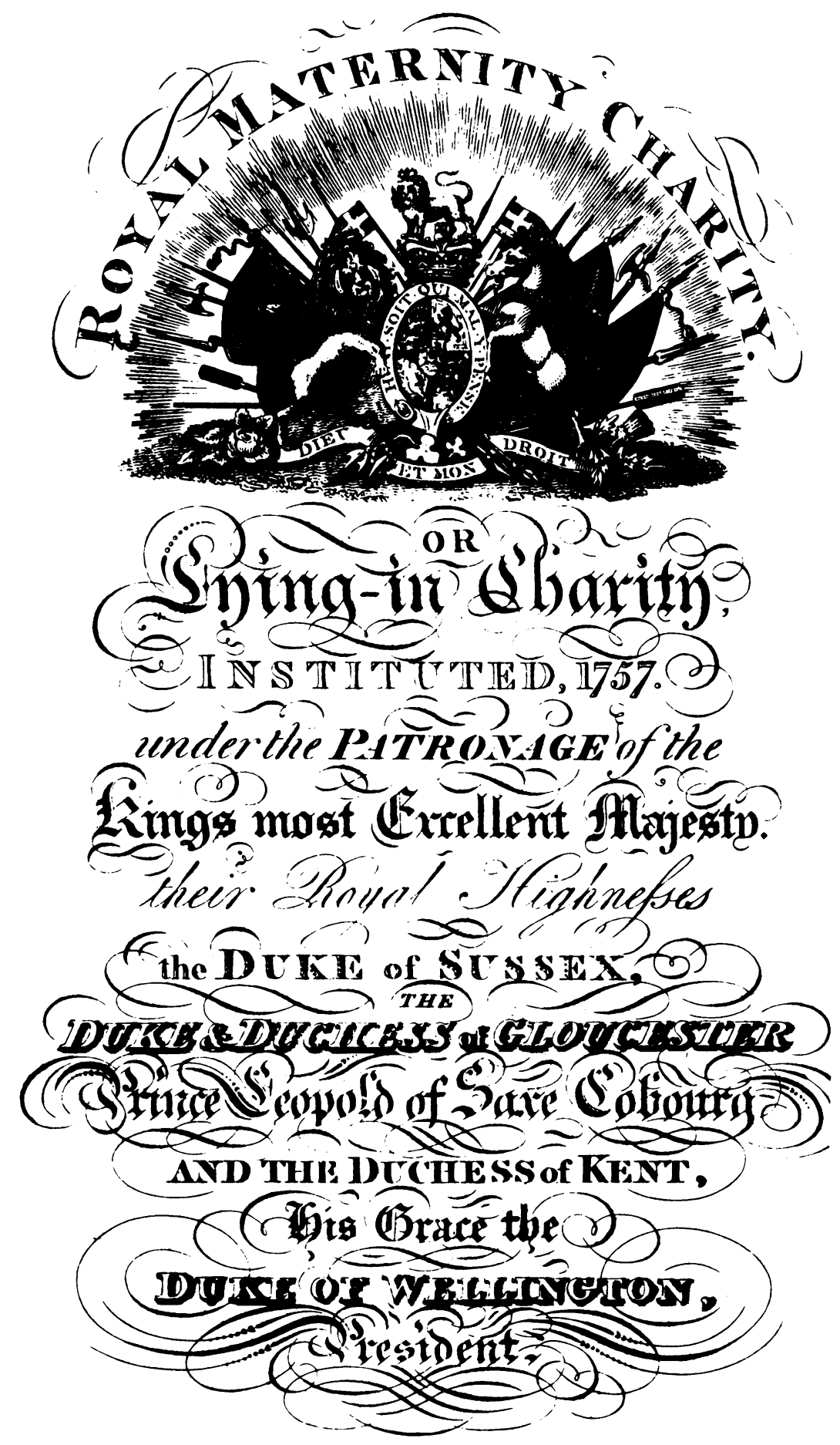

Figure 1. Frontispiece from Account of the Royal Maternity Charity for delivering Poor Married Women at Their Own Habitations, London, printed by A. Sweeting, Bartholomew Close, 1829. 


\section{The Royal Maternity Charity}

being changed to the East India Coffee House, also in Leaden Hall Street. The meeting was concerned with fund-raising, as a result of which the Reverend $\mathrm{Mr}$. Madan was persuaded to preach a sermon at St. Bartholomew the Great, West Smithfield, where $£ 29$ was collected. Afterwards, the subscribers and a considerable number of their friends dined together at the Shepperd and Shepperdess near the City Road, and $£ 6 \mathbf{1 8 s .} 0 \mathrm{~d}$. was collected, besides several new subscriptions. Subscribers to the Charity received tickets for distribution to the casual poor, entitling them to care which was provided by the Charity's medical officer, Mr. Tooley. Such subscriptions formed the principal source of finance for the voluntary hospital system in the eighteenth century. ${ }^{16}$

The work of the Charity was increasing, making it necessary to employ a second man-midwife. The number of deliveries by the Charity in the first four years of its existence, from Lady Day to Lady Day, was 35, 61, 135, 184. On 13 July 1761, Mr. J. $\mathrm{J}$. Ford ${ }^{17}$ was elected to the post and agreed to serve voluntarily until the funds of the Charity permitted a salary. Mr. Tooley was offered $£ 40$ per annum. He was already $£ 20$ in debt to two of the committee members, and had apparently been demanding fees from Charity patients. He asked for an increase in salary, and, when this was not forthcoming, "said no more but 'Good night Gentlemen', and withdrew."

- In 1763, the treasurer, Mr. Edward Webber, submitted his resignation, leaving debts of $£ 16916 s .10 d$. in the accounts, and was declared bankrupt, setting the precedent for a pattern which was to become all too common throughout the Charity's history. It took nine years before the Charity could recover $1 s .11 d$. in the pound on his estate, amounting to $£ 162 \mathrm{~s}$. $9 \mathrm{~d}$.

The work continued to grow, and in 1764, at the request of the committee, Dr. Ford submitted a plan to employ and train midwives. He proposed to have women of good character entirely under his direction. He would educate them and warrant them capable before they were employed by the Charity. Two women were appointed: Ann, the wife of Thomas Green, and Mrs. Sarah Moore. The characters of the women and their husbands being satisfactory, they were accepted for instruction at a cost of ten guineas each, to be returned if they served the Charity gratis for two years to the satisfaction of the committee. Within a short time it was necessary to appoint three more midwives. It soon became apparent that it was essential to allow the midwives some pecuniary assistance.

Dr. Ford reported that some of the midwives were in very low circumstances, in particular Mrs. Allen through the great call to the business of the Charity, had lost great part of her own business, which was ironing, and having two children depending on her for bread, she had not the where withal to refresh herself when she came home fatigued from a labour, after being up all night, and she also called one day on the treasurer and told him that she was so much employed in the Charity her two children must go to the parish.

It was agreed to allow the midwives $1 s .6 \mathrm{~d}$. for every woman delivered by them, to be paid monthly. The cost was offset by discontinuing the practice of giving money to the objects of the Charity, which had in several cases been abused. Compensation was

16 John Woodward, To do the sick no harm, London, Routledge \& Kegan Paul, 1974, p. 18.

17 William Munk, The roll of the Royal College of Physicians of London, London, Royal College of Physicians, 1878, vol. 2, p. 272. 
to be paid to women booked with the Charity, who were obliged to employ other midwives because the Charity's own midwives were engaged. Any midwife who refused to attend a booked labour, although available, would forfeit the sum of five shillings for every such offence.

In the year to Lady Day 1766, 1,073 were delivered by the Charity. A set of regulations for midwives was agreed:

1st. That every new midwife shall be obliged to live at whatsoever part of the town the committee shall think most convenient for the Charity. 2nd. That all midwives shall be under the direction of the man-midwife. 3rd. That every midwife shall attend those women whose tickets are signed to her: Unless she is at another labour or has given notice in writing to the doctor that she is sick: but if on either of these accounts she is not able to attend she shall then send the tickets to whatever midwife the doctor has ordered to supply in such cases: and if that midwife is not at home or if the bearer of the ticket should apply to any other midwife, she shall go with the person, as if the ticket had been directed to her. 4th. That in all cases where it is necessary to consult the doctor the midwives shall send a particular account thereof to him in writing. 5th. That after delivery the midwife is recommended to return thanks for the woman to almighty God, and afterwards give her a printed bill to be put up at her usual place of public worship for the same purpose. 6th. That the midwife shall attend every woman she delivers at least twice during her lying-in, and the first visit shall be paid within three days at farthest after she is brought to bed, at which time she shall open and dress the child as it is customary for midwives to do. 7 th. That no midwife shall presume to take of any tradesman, patient, servant, stranger or any other person any free reward or gratification, directly or indirectly, for any service done or to be done on account of the Charity. 8th. That no midwife go from her own house without leaving a plain direction in writing where she may be found. 9 th. That no midwife go out of town without leave from the committee. 10th. That the midwife shall not take the ticket from any woman till after she is delivered. 11th. That if any midwife is proved guilty of the breach of any of the above articles she shall be liable to such fine as the committee shall think necessary, or be discharged from the service of the Society. 12th. That the committee shall and will pay or cause to be paid unto each midwife one shilling and six pence for each woman at whose delivery or miscarriage the midwife shall attend in consequence of her trouble and care therein.

Despite the training given to midwives at the Charity and other similar institutions and lying-in hospitals, with the parallel opportunities for male practitioners, this era saw the decline of the midwife in status with the ascendancy of men, described vividly by Jean Donnison ${ }^{18}$ in her book portraying the history of inter-professional rivalries and women's rights. Disciplinary rules were necessary, since complaints against midwives were becoming increasingly common:

Mrs. Cecil was summonsed to answer a complaint against her from Mr. Hill of Sun Street Bishopsgate Street and he being called to declare what he had to say against the said Mrs. Cecil our midwife, he made it appear that he called her to his wife's labour about twelve oclock at night nov. 25. and that after knocking at the door, he heard somebody say, you shall not go, and was then answered out of the window by a man that Mrs. Cecil was gone to a labour, when he veryly believes she was at home. Mrs. Cecil being called upon to answer to the complaint, confessed that she was at home but not being very well, and expecting to be called to a labour of her own, made her not willing to go, and was the occasion of her husband giving that answer.

It being debated it was by the majority agreed that her offence being so heinous a nature she should be fined ten shillings, and also be discharged the service of the Charity.

At the next meeting, the committee relented, and changed the penalty to a fine of one guinea.

The accounts of the Charity from Lady Day (25 March) 1766 to 1 January 1767 show the financial state at that time. Collections, subscriptions, and donations raised $£ 517$ ls. $4 d$., to which was added Mrs. Cecil's fine. There were 1,204 women delivered

18 Jean Donnison, Midwives and medical men, London, Heinemann, 1977, pp. 34-36. 


\section{The Royal Maternity Charity}

at three shillings per head, and a further $£ 764 s .0$. was spent on medicines. Other outgoings were $£ 1212 s$. $0 d$. for stationery wares, $£ 1116 s$. $0 d$. for printing, $£ 1116 s$. $3 d$. for the secretary's salary for the nine months, and $£ 3115 \mathrm{~s}$. $1 \mathrm{~d}$. on advertising, committee meetings, and sundry expenses. These amounted to a further $5 s$. $5 d$. per woman delivered. One hundred pounds' worth of New South Sea annuities were purchased for $£ 88$, leaving a balance in hand of $£ 158 \mathrm{ls}$. $0 \mathrm{~d}$., which was $£ 1057 \mathrm{~s}$. $0 \mathrm{~d}$. more than the previous year. At that time the wages of a labourer averaged about ten shillings a week.

\section{ROYAL PATRONAGE}

In 1768, Queen Charlotte expressed her approbation of the Charity and indicated that she was most graciously pleased to permit His Royal Highness, the Prince of Wales, to become President thereof. A glowing address to the Prince was drawn up and delivered, ending: "May your bright example after a long display of active virtue be transmitted to posterity, by a numerous offspring! The ornament and glory of the British nation." This pious hope was not to be realized. His eventual marriage resulted in the birth of only one child, Princess Charlotte, whose tragic death was to involve the Charity in years to come.

In the year 1768, 2,868 women were delivered by the Charity. Of these, 152 required the assistance in labour of Dr. Ford, and a further 565 were seen by him for illness or during their confinements. This was straining the resources of the Charity. In view of the increase in work, Mr. William Cooper of Arundel Street in the Strand, and Dr. Thomas Cogan, No. 2 Old Broad Street, were accepted as assistant men-midwives to the Charity, under the direction of Dr. Ford. The previous year, the governors of the Westminster New Lying-in Hospital had felt unable to appoint Dr. Cooper as a consultant physician since he was not a member of the College of Physicians. ${ }^{19}$ At that time the majority of the members of the Apothecaries' and Surgeons' Companies practised midwifery, but it was considered desirable for those who held appointments at the lying-in hospitals to seek the licence of the College of Physicians. The College required that candidates for its licence to practise medicine should have obtained an M.D. degree and been disfranchised from the Apothecaries' or Surgeons' Companies if they were members. ${ }^{20}$ Throughout the history of the Charity, medical staff were elected, initially by ballot, by the laity, sometimes with a complete disregard for established medical convention.

In 1768 it was proposed to make large savings by patients providing their own phials for any medicine they might receive. Also, the number of objects each governor was entitled to recommend would be strictly limited to twenty within the year. The governors' tickets indicated the boundaries of the Charity, beyond which the midwives were not to go: "Millbank Westminster, Pimlico, Hyde Park Corner, Tyburn, Marylebon, Tottenham Court, Grays Inn Lane, City Road, Kingsland, Hackney, Bethnal Green, Mile End Turnpike, Limehouse Hole, Rotherhithe Church, Grange Road, Kent Street, Newington Butts, and Westminster Bridge Turnpikes."

19 Rhodes, op. cit., note 11 above, p. 30.

${ }^{20}$ Cecil Wall, The history of the Surgeon's Company 1745-1800, London, Hutchinson, 1937, p. 153. 
Much of the committee's time was taken up with complaints against midwives. Two were dismissed for claiming for deliveries which they did not attend. One presented a petition:

. . . begging pardon for her fault and setting forth her constant care in the discharge of the duty of her office, with the upmost tenderness and fidelity; Humbly begging to be restored to the service of the Charity in consideration of her large family of five children unprovided for, and promising, if her petition is granted that her future conduct should as far as possible be unexceptionable.

Despite this plea, it was decided that: “. . . the crime for which Mrs. Jones stood dismissed was of so heinous a nature that her petition to be restored could not be granted."

It was resolved to insert the following in the midwives' rules and orders: "Any midwife convicted of fraud shall be dismissed from the service of the society and rendered incapable for ever of being employed again by this Charity."

It was also resolved that: "Midwives belonging to this Charity are not obliged to attend objects in gaols or parish workhouses." This followed a report that "two of the midwives had been sent for, one to attend a person in a parish workhouse, and the other to a person in one of the compters, where she was kept all night under lock and key."

As the work of the Charity increased, so did its financial stability. "Dr. Ford ... had received for the benefit of the Charity $£ 1,000$ from The Right Honourable the Countess Dowager Gower, being as great a part of a legacy left by the late Earl of Thanet for charitable uses, as can be given by the trustees to any one institution." New subscriptions included: "Samuel Whitbread Esq., Portman Square $£ 11 s$. $0 d$. The Rt. Hble. Lady North, Downing Street $£ 11 s .0 d$."

The Charity was able to afford to appoint: "a proper person in the character of assistant clerk to the secretary, or door-keeper, or messenger, to attend the meetings of this society and do such business as comes within the province of such a character."

However, the secretary: "was distressed on account of many light guineas being offered him in payment for subscriptions. Resolved that such light money as shall be received for subscriptions by the treasurer and secretary, be kept by the treasurer and sold by him occasionally and such deficiency as shall thereby arise be allowed the treasurer in his accounts."

By 1772 , the annual deliveries had increased to over 5,000, nearly one-third of the registered baptisms in the Bills of Mortality. In 1774 an advertisement outlined the work of the Charity:

... the society employs three physicians and 27 midwives who are settled in the most convenient manner for attending the objects in all parts of this extensive metropolis: One of the physicians daily attends at No. 11 Pater Noster Row, Cheapside (being the most centrical part of the Town) to receive the objects, give them advice and assign their tickets to the midwife nearest their several situations there being eight midwives plac'd in the west end of Town, eight in London, eight at the east end of Town and three in Southwark by whom the poor are carefully attended and delivered and supplied with medicines before and after delivery; as also they are with the assistance of the men midwives when the case requir's it, one of whom lives near the Strand, one near St. Pauls and one farther east in the City.

The same year: "The great increase of objects applying to this Charity for relief, making every assistance necessary to its support; It was proposed that endeavours be used to obtain a play for the benefit of this Charity. Six gentlemen were elected a committee and desired to wait upon Mr. Garrick for that purpose." 


\section{PATIENTS, DOCTORS, AND MIDWIVES}

On 11 August 1774, Mrs. Elizabeth Foster, a patient of the Charity, went into labour with her ninth child. ${ }^{21}$ Born in 1738, she married when aged twenty and was soon pregnant. She had three easy labours in as many years, but the fourth was attended by such difficulty that the midwife declined to attend her any more, advising her to employ some gentleman of skill in midwifery. During that pregnancy she had a violent rheumatic fever for six weeks, following which she developed extreme weakness and deformity, diagnosed as mollities ossium. In the next three pregnancies she was delivered by Mr. Breach, an eminent surgeon of Tooley Street, Southwark. The life of the fifth child was preserved with great difficulty, but with the next two the pelvis was contracted so much in its dimensions that it was necessary to perforate the head to effect delivery. When in labour with her eighth child, she was a patient of the Charity, and was attended by William Cooper who "had to resort to the disagreeable operation of embryotomy ... the pelvis being somewhat less than two inches and a half from the symphysis to the superior projecting part of the os sacrum." By 1774 she appeared to be little more than an unwieldy lump of living flesh.

Mrs. Foster did not send for the midwife - Mrs. Saunders - until the morning of the 13 August 1774, when Mr. Cooper was called. He found: "The pelvis appeared so narrow and ill formed as not to admit of a possibility for the child (which was remarkably brisk and lively) to be delivered, even by the painful operation of embryulcia; the Caesarean operation seemed therefore the only alternative."

He sent for his colleagues from the Charity, Drs. Ford and Cogan. The patient was also seen by Drs. (William) Hunter, James Ford, Mackenzie, Orm, Bromfield, and Garthshore, and Messrs. Underwood, Graves, and Lowder. "They unanimously concurred in this opinion, That the Caesarean section was the only possible method for effecting the delivery."

At William Cooper's desire:

Mr. [John] Hunter, surgeon to St. George's Hospital, with the assistance of Mr. Patch, surgeon, of Norfolk Street, very readily undertook this disagreeable operation, the whole of which was conducted with the upmost coolness, humanity, and skill, in the presence of all the gentlemen before-mentioned. When the operator had made the wound into the uterus sufficiently open, I extracted the child by the feet as far as the neck, about which the womb instantaneously and strongly contracted, so as to retard the delivery of the head, and by pressing upon the funis umbilicalis, endangered the life of the child; $\mathrm{Mr}$. Hunter however with his hand soon overcame this stricture sufficiently for me to extricate the head. From this disagreeable circumstance, it was some time after the child was born before it could cry, when Dr. Cogan tied and divided the umbilical cord: and I finished the delivery, by taking away the placenta. During the whole of the operation, the poor woman behaved with remarkable patience and fortitude.

Elizabeth Foster died the following day, but four months later Dr. Cooper was able to write to William Hunter: "It is with sincere pleasure I add, that the child thus happily preserved to the community is still alive, and perfectly well."

No Caesarean section operation in England had so far resulted in survival for the mother, although a successful operation had been performed in the year of birth of Elizabeth Foster, 1738, in Ireland by Mary Donally, an illiterate woman but eminent among the common people for extracting dead births.

${ }^{21}$ William Cooper, 'An account of the Caesarean operation', Medical Observations and Enquiries, 1776, 5: $217-232$. 


\section{Stanley A. Seligman}

Following the death of Dr. Cooper in 1779 and the resignation of Dr. Cogan the following year, Dr. Andrew Douglas and Dr. John Sims were appointed to replace them, and in $1783 \mathrm{Dr}$. Richard Dennison was appointed as an additional physician for the eastern part of the town: "more especially as it will not be any additional expence, the physicians having upon requisition for their opinion, readily given up all idea of advantage to themselves, considering it as beneficial to the Charity."

Four years later, Dr. Ford retired, Dr. Douglas succeeding him as consulting physician, and Dr. John Squire being elected the new physician and man-midwife.

Throughout this time, complaints continued against some of the midwives, one of the commonest troubles being that of drunkenness.

There being strong reason to think Mrs. Bursnote is addicted to drinking, resolved that she be not reengaged in the service of the Charity. Dr. Dennison then reported that he had been sent for to a labour by Mrs. Bigg, whom he found very much intoxicated with liquor. The consequences of drunkenness in a midwife being so exceedingly dangerous, resolved that Mrs. Bigg be discharged the service of the Charity.

A complaint then being laid against Mrs. Ross for neglect of Mrs. Etherway (mother and baby died). Mary McDaniel (the complainant) was asked what liquor was drunk that night. She said 12 at night, a pot of twopenny and half a pint of gin was fetched, the beer was drunk by Etherway and the gin by the watchman, the husband and Ross, and some left. No gin was put into the twopenny. Resolved that Mrs. Ross be suspended till the next committee night [at which she was reinstated].

There was also some bickering among the midwives themselves: "Mrs. Middleton, Mrs. Kemble and Mrs. Haliburton were acquainted from the chair, that they must not circulate reports prejudicial to each other, as it might ultimately affect the Charity; but if they knew of any material misconduct of a Charity midwife, they should acquaint the treasurer."

In 1792, Dr. Richard Croft was appointed physician and man-midwife, having:

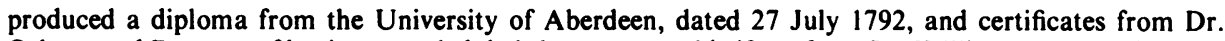
Osborn and Denman of having attended their lectures on midwifery; from Dr. William Hunter, of having attended his anatomical and chirurgical lectures; from Dr. Fordyce, his lectures on chemistry and materia medica; and from the Company of Surgeons London, dated 17 May 1791, a certificate of his being a proper person to act as a surgeon.

In 1783, the College of Physicians had instituted an examination for a licence to practise midwifery, and it was considered desirable for those who held appointments at lying-in hospitals to seek this licence. It was necessary for them to hold an M.D. degree and to be disfranchised from the Apothecaries' or Surgeons' Companies if they were members. ${ }^{22}$

In 1795, the Prince Regent married Caroline of Brunswick. An address was drawn up for their Royal Highnesses the Prince and Princess of Wales, which was rewarded by her patronage.

An entry in 1800 shows the medicines in use, together with their costs:

Anodyne mixture, per gallon, 6/-; cordial mixture, per gallon, 6/-; oleaginous emulsion, per gallon, 9/-; anodyne acid drops, per pound, 8/-; volatile anodyne linament, per pound, 12/-; febrifuge powders, 4 papers, $6 d$; contraerva powders, 6 papers, $6 d$; rhubarb powders, 6 papers, 1/-; anodyne pills, no. 24, 9d; laxative electuary, per pound, 5/4. Prescriptions extemporaneous in general allowing for the difference

22 Wall, op. cit., note 20 above, p. 153. 


\section{The Royal Maternity Charity}

in the composition of medicines if they exceed (as they sometimes do) in price the sum annexed. A draught, $6 d$; box of pills under and to $12,6 d$; do from 12 to 24 and so on, $9 d$; alliummon electuary, fl. oz., $3 d$; electuaries with bark, fl. oz., $6 d$; liniments in general, fl. oz., $4 d$; blisters from 3 to $9 d$; cerate for blisters, fl. oz., $3 d$; ointment for perpetual, fl. oz., $6 d$; castor oil, fl. oz., $6 d$; balsam of capivi, fl. oz., $6 d$; simple lotions, 4 ozs., $6 d$; do with sp. vini., fl. oz., $3 d$; mixtures from $8 d$ to $1 /-$.

One of the bills ordered for payment was: "Mr. Benjamin Dunscombe for bleeding $£ 2: 8: 0 . "$

On 19 February 1818, the treasurer reported the decease of Sir Richard Croft, Bart., one of the physicians of this Charity. Behind this announcement lay the obstetric management culminating in the death of Princess Charlotte Augusta. Overcome with remorse, Sir Richard Croft, the accoucheur at the royal confinement, shot himself. Croft and another of the doctors concerned, Matthew Baillie, the royal physician, were brothers-in-law, married to the twin daughters of Dr. Thomas Denman, a powerful advocate of the conservatism in obstetrics which was responsible for the death of the princess and her child.

Dr. John Sims, Croft's senior colleague from the Charity, was called in as consulting accoucheur when the labour became prolonged. He was also physician to the Surrey Dispensary and Charity for delivering Women in their own Houses, and to the Establishment for Diseases of the Ear. In addition, he was a distinguished botanist, and editor of the Botanical Magazine. In view of these widespread interests, Sir Eardley Holland ${ }^{23}$ has cast doubts on Sims's ability as an obstetrician, but the minutes of the Royal Maternity Charity show Sir Eardley's doubts to be unfounded. Dr. Sims absolutely refused to sign the certificate of the death of the princess, ${ }^{24}$ lending support to the theory that her death was due to poisoning by order of her father, the Prince Regent.

Sir Richard Croft was replaced in the Charity by Dr. Richard Byam Dennison, son of a former physician to the institution. He joined Dr. John Ramsbotham and Dr. David Daniel Davis, elected in 1814 and 1816 respectively.

The committee continued to be plagued with complaints about the drunken and rebellious behaviour of a minority of the midwives. However, other officers of the society were not immune from fault. At a meeting in 1820, a letter was read from $\mathrm{Mr}$. Blackelock of Sergeants Inn, Fleet Street, solicitor to Mr. Thompson, the Charity's treasurer: "Gentlemen, I am sorry to inform you that in consequence of unpleasant circumstances which occurred in the affairs of your treasurer, Mr. Thompson on tuesday, he has been under the necessity of suspending his payments and that he will not have it in his power to attend the committee this evening." Examination of the cash book revealed that there was a deficit of $£ 1,3854 s$. $11 d$. due from Thomas Thompson.

The following year: "Jeremy Garfield, collector and messenger, having pleaded guilty to an indictment charging him with vending silver spoons on which the hall stamp had been forged, and sentence having been passed upon him for fourteen years transportation, is dismissed from his situation with this Charity."

${ }^{23}$ Eardley Holland, 'The princess Charlotte of Wales: a triple obstetric tragedy', J. Obstet. Gynaec. Br. Emp., 1951, 58: 905-919.

${ }^{24} \mathrm{~J}$. J. Green, 'A Quaker medical trio named Sims, and some account of that family', Friends Quarterly Examiner, 1913, 43: 265-293. 


\section{Stanley A. Seligman}

THE CHARITY BECOMES ROYAL

On 25 March 1824, it was resolved that: "this Charity be in future designated The Royal Maternity Charity For Delivering Poor Married Women at their own Habitations. Formerly known as The Lying-in Charity For Delivering Poor Married Women at their own Habitations."

This was agreed at a special general meeting held for the purpose on 14 April, when the name was changed as advised: "in order to distinguish this most excellent and unrivalled Charity from others of posterior date and less extensive power to do good." The change of title was notified in four morning and two evening daily papers, and incorporated into the Charity's communications and advertisements.

In 1827, Dr. John Sims, M.D., F.R.S., F.L.S., retired after serving the Royal Maternity Charity for forty-seven years. Dr. Francis Henry Ramsbotham was elected in his place, joining his father, John, and Drs. Daniel Davis and Richard Byam Dennison. When the latter resigned in 1833 , one of the candidates for the vacant post was Dr. Michael Ryan. The letter in which he offered himself as a candidate was an incredible document of over 1,100 words in length:

.. I have been in the profession since 1815 and received my medical education in Dublin, Edinburgh,
London and Paris; while the Degree and Diplomas which I possess and place before you are the follow-
ing: I The Degree of M.D. from the University of Edinburgh. 2 The Diploma of the Royal College of
Physicians in London. I decline presenting my surgical Diplomas. If you refer these documents to your
distinguished Medical Officers, who are eminently qualified to estimate their value and importance, I am
induced to think that they will inform you that few members of the medical profession prosecute the
laborious studies, or incur the great expense requisite for the acquirement of so many qualifications, and
from the highest sources in the British dominions. They will also apprize you that there is a vast
difference between such testimonials and those granted by insignificant and disreputable universities...
I trust that the time has gone by, when money and not talent, will be the passport of medical
practitioners into our establishments I have not employed electioneering tactics or trickery which I
despise; I offer myself to your notice on the grounds of professional qualifications and reputation alone.
Allow me to observe, in conclusion, that as a member of the Royal College of Physicians in London, or,
in other words, as a legally qualified Physician, I am entitled to your entire support. In common with all
citizens it is your duty to respect and uphold the laws of the country; and therefore you cannot admit on
the same terms with myself, without opposing the laws of the land, one of the rival Candidates, who is
not a member of the College, who is an illegal practitioner as a Physician in London, and is liable to
prosecution for practising in this metropolis. Moreover, it would be unjust, as well as illegal, on your
parts, to deprive me of the advantages which the law of the realm confers on me; or to transfer these
advantages to one, who, however numerous his friends may be, has yet to attain my rank and station in
the medical profession.

However, three weeks later, on mature consideration, Ryan retired from the contest with a brief letter offering his warmest thanks to those governors who supported him as a candidate. Dr. Thomas Leigh Blundell, M.D., from the University of Glasgow, was elected to the vacant position. The gentlemen who elected him were not to know that Dr. Ryan's dire warnings were to bear fruit in later years.

This was an era when obstetricians, (a term first used by Michael Ryan), were fighting to achieve status. In 1825, the short-lived Obstetrical Society was formed to raise to a proper and dignified station the practitioners in midwifery. ${ }^{25}$ This was against the opinion of men such as Sir Henry Halford, President of the College of

${ }^{25}$ J. M. Munro Kerr, R. W. Johnstone, and Miles H. Phillips, Historical view of British obstetrics and gynaecology 1800-1950, Edinburgh, E. \& S. Livingstone, 1954, pp. 312-313. 


\section{The Royal Maternity Charity}

Physicians, that "Midwifery was an unfit occupation for gentlemen of an academical education", and Sir Anthony Carlisle, later President of the College of Surgeons, that man-midwifery was a "dishonourable vocation".

The Royal Maternity Charity, along with similar smaller institutions, was providing the poor women of London with a service which was more extensive, safer, and more economic than the lying-in hospitals. Some of the governors of the Middlesex Hospital, in 1749, had pointed out that "a lying-in woman costs twice as much as the sick and lame." ${ }^{26}$ In 1818, Dr. Granville, founder of the Obstetrical Society, had shown how in the four London lying-in hospitals, a total of about 1,400 women were delivered yearly at a cost of $£ 312 \mathrm{~s}$. 10d. per woman, or enough to relieve sixteen poor married women during their confinements with the Westminster General Dispensary. ${ }^{27}$ In 1828, 4,253 women were delivered by the Royal Maternity Charity for a total expenditure of $£ 1,64311 s$. $1 d$., or $7 s .9 d$. per patient. To reduce the cost still further, the medical committee looked into charges for medicine, which they thought to be unnecessarily high, and recommended that the price of many items be reduced and that: "each medical officer be furnished with a copy of the Charity's pharmacopoea and 'requested to adhere as closely as he conveniently can to the forms there prescribed"." However: "Your sub-committee, on agitating the question of the charge which should be allowed for leeches; declined to fix a price on them, since their value varies so much at different seasons of the year."

The "medical officers" alluded to in this report formed a new venture for the Charity. In 1834, a sub-committee was appointed to enquire whether or not there was any necessity for further medical assistance to the physicians of the Charity. They decided such assistance was necessary and advised the appointment of two or three surgeon accoucheurs, the same being members of the College of Surgeons, and licentiates of the Apothecaries' Company, residing within each district. Nine such assistants were elected to help the physicians.

In 1837, on the death of King William IV, an address was presented to Queen Victoria, signed by the Duke of Wellington, president of the Charity:

it was the first institution of its kind established in the Metropolis, and to the present period has conferred its benefits upon 315,193 poor women entitled to its protection.... We, the representatives of the Royal Maternity Charity, feel deeply grateful for the countenance and assistance vouchsafed to it by your Majesty's Royal Relatives, and, relying on your Majesty's gracious condescension, well known benevolence, and sympathy for the distress of all classes of your Majesty's subjects, most dutifully and humbly submit this concise statement of it to your Royal Consideration, earnestly praying that your Majesty will deign to afford your Royal patronage to this extensively useful Institution.

The address was very graciously received but: "I have to express my regret that in consequence of the very great number of applications for patronage Her Majesty cannot be advised to consent to be the Patroness of this Institution." Following this reply, the proposed circulation of the printed address to the queen was suspended. However, in 1847 , she gave her consent to becoming patron.

In 1839, the committee set up a fund for the superannuation of midwives. Each midwife would contribute one penny out of her pay for each delivery, for which the

${ }^{26}$ Gunn, op. cit., note 5 above, p. 80.

${ }^{27}$ Granville, op. cit., note 12 above, pp. 16-17. 
funds of the Charity would pay three pence. Midwives would not be able to benefit from the fund unless they had been in the service of the Charity for fifteen years, and had contributed towards it for five years. Each superannuated midwife would be allowed $£ 1$ a month from the fund, or more, should the accumulations admit. Any midwife who resigned, or was discharged for misconduct, would be deemed incapable of partaking of the benefits of the fund, but would have the gross sum of her subscriptions returned to her without any deduction whatsoever.

The same year Mr. Jas. C. Millar resigned from his post as surgeon accoucheur to the Charity, following a mishap.

It is the opinion of several medical friends whom I have consulted, that if a physician had seen the woman sooner, the most of the mischief would have been avoided as it was a case wherein the assistant surgeon was not authorised to act without a consultation. Mrs. Dennison ought certainly to have gone to Dr. Ramsbotham when I desired her at 1 o'clock in the morning, instead of going backwards and forwards until nearly 6 o'clock, when she went to Dr. Ramsbotham and he refused to attend. She, then, as I am told, went to $\mathrm{Mr}$. Lewis again and, from him to Dr. Blundell, who visited this woman about 8 o'clock, thus allowing seven hours of valuable time to pass. It is very evident that Dr. Blundell has been much annoyed, and thought it a good opportunity to bring a charge against Dr. Ramsbotham who turned it off on account of some old standing rule of the society, wherein he was not obliged to attend with a midwife belonging to Dr. Blundell. The whole of the parties concerned now turn their share of the blame upon me.

The committee requested Dr. Davis to investigate the circumstances of the case. Following his recommendations, it was resolved that:

every midwife should be directed to apply always when she requires assistance to the physician or one of the surgeons of her own district. That the physicians form the medical board of this Institution; and that on future election as assistant surgeon, he be examined by at least two of them previous to his being elected.

Although the circumstances behind these statements are not given, they indicate a deep difference of opinion between the obstetric physicians and the surgeon accoucheurs. Although the physicians closed ranks when confronted with the allegations, it also seems that they were divided among themselves. It is quite possible that Dr. Ramsbotham did not regard Dr. Blundell as sufficiently qualified to occupy his position with the Charity.

There was suspicion that some midwives might be submitting claims for fictitious deliveries, and it was resolved:

That the messenger shall be required to visit one or more patients in each month of every midwife having five cases within the month, and any others which the secretary shall point out; so that there shall not be less than 35 cases examined into within each month; and that the said messenger shall deliver a report to the committee of the results of such enquiries, where fraud is detected, at the first meeting in January.

In 1845 it was resolved that the sum of $£ 150$ be given to the secretary (Mr. Wilson) as a gratuity for his great exertions for the benefit of the Society during the last twenty-five years. The following year the chairman reported the death of Mr. Wilson (as reported in the "Times Paper" of 28 April 1846). A sub-committee was formed to consider and arrange the duties of secretary. They reported:

That they are compelled to believe that Mr. Wilson is not dead and the statement in the "Times" is fictitious and inserted for some interested purpose. That a Mr. Buck of 31 Merrow Street Walworth having been employed by Mr. Wilson to collect subscriptions in the month of April came in the most straight-forward manner and gave evidence of his having paid the said $\mathrm{Mr}$. Wilson money which he had collected, which money is not accounted for and upon that evidence a warrant has been obtained and put into the hands of Mr. Inspector Boyd for the apprehension of the said Mr. Francis Wilson. 


\section{The Royal Maternity Charity}

Efforts to trace him proved fruitless.

Five years later, the secretary, Dr. Ottney Rayner, retired, shortly after which irregularities were discovered in his accounts. It was to be another six years before his most audacious theft was discovered.

\section{PHYSICIANS AND SURGEONS}

The surgeon accoucheurs were becoming dissatisfied and, in 1847, they demanded that they be remunerated for their work. The views of the physicians were sought.

Dr. Francis Ramsbotham decidedly objected: "on the implied presumption that they stand, as regard the Charity, on a perfect equality with the physicians ... this assumed position is one to which I cannot accede ... they can only be considered as 'assistants'."

Dr. Hall Davis approved entirely: "that they be remunerated for their services.... I do not coincide in the suggestion that the payment of the physicians and the surgeons should be equal, because it is entirely contrary to the practice and etiquette of the profession."

Dr. Blundell thought: "that the surgeon accoucheurs are entitled to remuneration for their valuable assistance after a certain period of servitude ... but I cannot coincide with their views in wishing to be placed upon an equal footing of rank and remuneration with the physicians as such an arrangement would be incompatible with and totally subversive of the original intentions of the founders of the Charity, which were that the responsibility should rest with the physicians, the surgeons being only required to attend urgent cases in the unavoidable absence of the physicians."

Dr. Ramsbotham had been averse to the appointment of assistant surgeons at the time this addition was proposed, being very conscious of the status bestowed on him as a Fellow of the Royal College of Physicians, but all three physicians obviously resented that the surgeons be paid for mere technical work. Nevertheless, the committee agreed to remunerate the surgeon accoucheurs after they had served the Charity for five years, the sum calculated at one shilling for every woman delivered by the Charity, to be divided between them. By 1850, the Charity was running into financial difficulties and the surgeon accoucheurs agreed to a reduction in their remuneration. The physicians followed their example.

In 1852, when Dr. Francis Ramsbotham resigned, the area covered by the physicians was rearranged so that Dr. Blundell took over the vacant district. He complained: "that Dr. Burchell of the Kingsland Road, one of the Charity's surgeon accoucheurs, refuses to meet him at any time professionally in the business of the Charity."

Seven surgeons of the district explained that they refused to act with him personally because: "you are not a Licentiate of the Royal College of Physicians and are disqualified for the position you hold as physician to the Royal Maternity Charity."

Dr. Blundell, in reply, referred to his twenty-three years' service with the Charity. The committee resolved that: "Inasmuch as Dr. Blundell has creditably filled the office of physician to the Royal Maternity Charity since 1833, to which office he was elected by the governors generally, this committee have no power nor desire to disturb Dr. Blundell in that position." 
This resolution having been carried, the following protest was presented by Mr. Jas. Bamford: "I protest against the resolution because Dr. Blundell is not qualified to continue a physician as not being in accordance with the present rules of the Institution, and not being either Licentiate or Fellow of the Royal College of Physicians of London."

On being informed of the resolution, the seven surgeons resigned. At the half-yearly general meeting in August 1853, Mr. Bamford gave notice that at the next general meeting he would move the following resolution:

That it is the opinion of this meeting that it will be to the interests of the Charity and a great convenience to the midwives and poor patients to discontinue on and after February 1854 the services of the physicians, having found of late great danger arise to some of the patients from their living at considerable distance from these professional gentlemen (and others from moral necessity having been called in) and where time has permitted even the midwives to send for them, they have frequently been represented absent or unable to attend from other causes - and for these reasons it is desirable to adopt a more immediate and continuous system of medical relief when required by the midwives.

This was noted by the Lancet $^{28}$ in a full-page editorial fiercely attacking $\mathrm{Mr}$. Bamford. Undeterred, he replied ${ }^{29}$ with a letter strongly criticizing the physicians "so called by courtesy, two of them at least, if not all, not being known at the Royal College of Physicians of London." Furthermore, he wrote: "During the six months from February 5 to August 5, 1850, these gentlemen attended or visited eight cases, for which professional services they took out of the funds of the charity no less a sum than $\mathbf{f 9 0 . "}$

A bitter correspondence ensued over the next six months; however, in one of the letters ${ }^{30} \mathrm{Mr}$. Bamford disclosed: "in 1851, Dr. Blundell made voluntarily to the chairman of the committee an offer to provide all the professional assistance necessary, and to take the entire responsibility upon his own shoulders for $£ 100$."

Despite Dr. Blundell's initial denial of this accusation, ${ }^{31}$ and later explanation of it, ${ }^{32}$ his statements were emphatically and unequivocally contradicted..$^{33}$ It was disclosed that this was the true reason behind the resignations of the seven surgeons. Undeterred, Dr. Blundell continued in his post and, in 1856, wrote to the committee reminding them that until the death of Dr. John Ramsbotham the senior physician was invariably elevated to the post of "consulting physician", enjoying the stipend attached thereto, and recommending that the practice be renewed. The committee did not agree. The next year, following another request from Dr Blundell, and in view of his advanced age, he was appointed consulting physician to the Charity, the salary attached to the office being $\mathbf{f} 60$ per annum. Dr. Robert Barnes was elected to fill the vacancy on the district, and was soon joined by Dr. J. Braxton Hicks. Dr. Blundell died in 1872, after which the post of consulting physician was allowed to lapse.

\section{CENTENARY CELEBRATIONS}

The year 1857 marked the Charity's centenary. In its first 100 years the Charity had

${ }^{28}$ Editorial, Lancet, 1853, ii: 147.

29 James Bamforth, ibid., 227.

${ }^{30}$ Idem, ibid., 323-324.

31 Thomas Leigh Blundell, ibid., 590.

${ }^{32}$ Idem, ibid., 1854, i: 22.

${ }^{33}$ Editorial, ibid., 135. 


\section{The Royal Maternity Charity}

cared for 385,488 poor women. In the last year 3,297 had been delivered, including fifty-three cases of twins and three of triplets. Only two women died within a month of labour, including one from pulmonary consumption, and this at a time when the hospitals of London, Vienna, Paris, and Dublin were ravaged by childbed fever. The role of doctors in spreading this fatal disease was not yet understood, and many obstetricians showed frank disbelief that the Charity's statistics could be reliable. This implied that midwives' results were superior to those of "educated accoucheurs". ${ }^{34}$ During the same year, the four London lying-in hospitals - Queen Charlotte's, the City of London, York Road, and the British Lying-in - had cared for only 1,030 patients between them at a cost of the lives of fourteen of the mothers. ${ }^{35}$ It is probable that one of the reasons for the comparative safety of deliveries in the Charity was the system of skilled midwives being responsible for the primary care of patients, the accoucheurs only being called when necessary. Dr. George Roper, another physician of the Charity, in 1879, contrasting the deliveries in the Charity with those in the Rotunda Lying-in Hospital under two masters with very different approaches, showed how a high forceps rate was accompanied by a high foetal and maternal mortality..$^{36}$ Under the Royal Maternity Charity's system unnecessary obstetric intervention was avoided. When complications did arise, skilled obstetricians were available, and a case-book of the patients referred to Dr. Robert Barnes has survived and shows the high standard of specialized care available. ${ }^{37}$ The control by the midwife and the absence of medical students avoided much unnecessary obstetric interference.

A centenary festival was held, presided over by the Duke of Argyll. A memorial was sent to Queen Victoria praying for a gracious contribution to the festival fund. This brought a quick reply from Buckingham Palace:

Sir, I beg to acknowledge the receipt of your letter of the 14th instant, together with its enclosures. The tenor of your letter would lead to the supposition that Her Majesty the Queen had made no donation to the funds of the Royal Maternity Charity and I have been rather surprised on referring to the report forwarded to find no mention of Her Majesty's donation of fifty guineas. It appears to me that there must be some mistake. I am Sir, Your obed. humble Servt., C. B. Phipps.

Investigation with the help of Colonel Phipps made it apparent that Dr. Rayner, the former secretary, had intercepted the cheque in 1848! The queen subscribed fifty guineas for the festival fund.

The Royal Maternity Charity had achieved an eminent position as the main single agency responsible for the care of the pregnant poor of London. It was to continue in existence for nearly another century, bringing maternity care to a total of over 604,000 women of the metropolis. However, forces were already at work which would lead to its eventual disbandment. During the past 100 years the economy of Great Britain had changed from one based on agriculture to one founded on the age of coal and iron. The Crimean war had ended, making Florence Nightingale a national heroine and initiating a different attitude to the art of nursing which would transform

\footnotetext{
${ }^{34}$ Donnison, op. cit., note 18 above, p. 58.

${ }^{35}$ Kerr, Johnstone, and Phillips, op. cit., note 25 above, p. 263.

${ }^{36}$ George Roper, The Royal Maternity Charity London. A statistical account of the deliveries in the eastern division of the Charity during the years 1875-76-77-78, London, A.T. Roberts, 1879, pp. 3-16.

${ }^{37}$ Stanley A. Seligman, 'Robert Barnes' case book from the Royal Maternity Charity 1857-1868', Practitioner, 1979, 223: 281-286.
} 
it from a menial employment to an honoured vocation; leading in 1902 to the passing of the Midwives Act, establishing the Central Midwives Board, with local supervision of midwives passing into the hands of Medical Officers of Health. Although the charity continued to flourish throughout the nineteenth century, its death knell was sounded by the social legislation of the twentieth century, which reduced the number of women who needed the Charity's services and the voluntary contributions on which it depended.

With the advent of the National Health Service in 1948, the service provided by the Royal Maternity Charity became redundant. The Ministry of Health suggested that the Charity affiliate with one of the organizations undertaking home nursing in the London area. Accordingly, the investments of the Royal Maternity Charity were transferred to the official trustee of charitable funds, to be used for grants to the executive committee of the Central Council for District Nursing in London, a coordinating body for the London district nursing associations, thirteen of which undertook midwifery in the patients' own homes. The last meeting of the committee took place on 9 June 1949. The place of the Royal Maternity Charity in the history of the metropolis is best described in the words of a former president, the Duke of Wellington: "All London is the Charity's Hospital and every street a ward."

\section{SUMMARY}

THE CHARITY for attending and delivering poor married women in their lying-in at their respective habitations was instituted in 1757, in an age which saw the introduction of skilled maternity care for the poor of London. Founded by James Le Cour, it employed medical officers who educated women of good character as midwives. During the 192 years of its existence, over 604,000 women in labour were cared for by its midwives and doctors. Funds were provided by subscriptions and charitable functions. The Charity soon won royal patronage and, despite troubles with embezzling administrators, drunken midwives, and quarrelsome physicians, continued to flourish. Many of the leading obstetricians of the day were physicians to the Charity, including those associated with the death in childbirth of Princess Charlotte. During the first hundred years of its existence it was the main agency responsible for the care of the pregnant poor of the metropolis, tending a much larger number of women than did the lying-in hospitals and with the loss of fewer lives. 